Fecha de recepción: octubre 2021

Fecha de aprobación: noviembre 2021

Fecha publicación: diciembre 2021

\section{La identidad desde la otredad}

Silvia Gabriela Zeas Carrillo ${ }^{(1)}$

Resumen: En un acercamiento por conocer cómo construimos una identidad propia que se reconoce desde la existencia del otro, una construcción que se alimenta del contexto que la rodea y de las relaciones en las dinámicas sociales, se analizan planteamientos de varios autores como Hall, Wilde, Briones y Ulloa, para llegar a analizar en la dinámica cultural, a la identidad reconocida desde la otredad en los códigos vestimentarios de la moda desde los análisis de Simmel, Veneziani, Saulquin, entre otros.

Palabras clave: Identidad - moda - otredad - dinámica social - códigos - vestimenta - cultura - sociedad - historia - sociología.

[Resúmenes en inglés y portugués en la página 74]

(1) Máster en Proyectos de Diseño de la Universidad del Azuay y Master in Fashion and Textile del Instituto Europeo de Diseño-Italia, Doctoranda en Diseño de la Universidad de Palermo. Es Coordinadora de la Escuela de Diseño Textil e Indumentaria de la Universidad del Azuay, Cuenca, Ecuador.

\title{
La identidad desde la otredad
}

Desde hace miles de años, el hombre encontró en las pieles de animales, fibras naturales y tejidos con fibras recursos para cubrir su cuerpo de las adversidades del clima, de los animales y de los mismos humanos; estos recursos dependían del contexto donde se situaban, en los climas cálidos y húmedos se empezaron a entrelazar hojas, ramas, semillas y cortezas para crear prendas, además las ornamentaciones con plumas, collares y pieles de animales se usaban como un distintivo de jerarquía; en los climas fríos encontraron en las pieles, fibras y pelos de animales el abrigo para cubrir su cuerpo, el uso de pieles animales exuberantes marcaba a los líderes sociales.

Con el avance de las civilizaciones convirtieron el entrelazamiento de las fibras naturales en técnicas de tejeduría de punto, plano y no tejidos que prevalecen en el tiempo, la producción industrial apertura el surgimiento de fibras sintéticas y artificiales. Mientras la producción textil crecía, las prendas adquirían un valor simbólico de distinción entre cla- 
ses sociales, culturas, ideologías, etnias, género y otros aspectos sociales. El valor simbólico de la indumentaria se convirtió en un medio de comunicación de una identidad individual y a su vez de una identidad colectiva, y en este marco la construcción de la identidad. Existen muchos nudos problemáticos dentro de los procesos de formación de la identidad, desde las distintas disciplinas que estudian a los individuos, se cree que hubo una influencia desde la psicología hacia la antropología por la frecuente confusión entre identificación personal y su reconocimiento hacia una etnia en particular, en la que se transfieren características de lo individual a lo colectivo (Wilde, 2009); podemos hablar entonces de una identidad cultural que reconoce a cada individuo pero lo integra en un colectivo particular. En la búsqueda de este reconocimiento son varias comunidades que luchan por preservar su identidad cultural, desde su ideología, sus orígenes, sus tradiciones, sus costumbres, su vestimenta, su historia es decir todas las manifestaciones culturales que han formado en ellos un sentido de pertenencia hacia sus comunidades.

La aparición de las nociones de individualidad, en el sentido moderno, puede relacionarse con la ruptura del orden social económico y religioso medieval. En el movimiento general contra el feudalismo, se colocó un énfasis nuevo sobre la existencia personal del hombre por encima de su lugar o función en una sociedad rígidamente jerárquica. Hubo un énfasis similar en el protestantismo, que se colocó sobre la relación directa e individual del hombre con Dios y no sobre una relación mediatizada por la iglesia. Pero no fue sino hasta fines del siglo XVII y el siglo XVIII que un nuevo modo de análisis, en la lógica y en las matemáticas, postuló al individuo como la entidad sustancial, de la cual se derivan otras categorías colectivas.

En el siglo XVIII apenas era posible imaginar los grandes procesos de la vida moderna como centrada en el sujeto-de-razón individual. Pero cuando las sociedades modernas fueron creciendo en complejidad, adoptaron una identidad más social y colectiva. Las clásicas teorías de gobierno liberales, basadas en los derechos y el consentimiento del individuo, fueron obligadas a aceptar las estructuras del estado-nación y con las grandes masas que construyeron una democracia moderna. Las leyes clásicas de economía política, propiedad, contrato e intercambio tenían que operar, después de la industrialización, en medio de la gran formación de clases del capitalismo moderno. Entonces emergió una concepción más social del sujeto. El individuo llegó a considerarse como el más ubicado y situado dentro de las grandes estructuras y formaciones de soporte de la sociedad moderna.

El declive de las viejas identidades que se estabilizaron en el mundo social durante tanto tiempo dio nacimiento a nuevas identidades, fragmentando al individuo. A este declive, Hall lo llama crisis de identidad, que conlleva dislocar procesos y estructuras centrales de las sociedades modernas, y la razón de su estudio es explorar esta problemática desde sus conceptos a implicaciones culturales, étnicas, raciales, lingüísticas, religiosas, de clase y de género (Hall, 1992); en este declive el individuo encuentra otras formas para interactuar en la sociedad, se reconoce al individuo como creador de la sociedad.

Según Hall (1992) la época moderna dio origen a una forma de individualismo: vivida, experimentada y conceptualizada de forma diferente, arrancando al individuo de sus tradicionales estructuras, ya que se creía que todo era designio divino, este cambio fue generado en su mayor parte por el Renacimiento del siglo XVI y la Ilustración del siglo XVIII, en este contexto encontramos a grandes filósofos, como Descartes y John Locke; 
pasando luego por el período de industrialización y al aparecimiento de clases sociales en los sistemas de producción, lo que generó una concepción más social de individuo y que dieron lugar al nacimiento de las ciencias sociales como la psicología, la antropología y la sociología, que enfocan al ser humano como objeto central de sus estudios, desde este ámbito se agrega la noción de otredad donde se reconoce la existencia de otro, para que los individuos asuman su propia identidad.

La concepción moderna de la temática de identidad, es el rechazo a las tradicionales formas de abordar el tema, enraizadas en un esencialismo que impedía la transformación de la identidad y negaba todo cambio que existía hasta los albores de los años ochentas a noventas (Wilde, 2009), puesto que el mundo cambiante en el que vivimos revela la falta de operatividad de los conceptos de las ciencias sociales, y mucho más dentro del campo de la identidad; este re direccionamiento reconoce un dinamismo de la cultura, donde los individuos interactúan y se transforman.

\section{Construcción de la identidad desde la otredad en la indumentaria}

Según Lacan la formación del yo en la mirada del otro inaugura la relación del niño con sistemas simbólicos externos a él y, de este modo, da inicio a la entrada de este a varios sistemas de representación simbólica, que incluyen el lenguaje, la cultura y la diferencia sexual. Los sentimientos contradictorios y no-resueltos que acompañan a esta difícil entrada son aspectos clave de esta formación inconsciente del sujeto, que lo dejan dividido y que permanecen con éste durante toda la vida. Sin embargo, a pesar de que el sujeto está siempre roto o dividido, experimenta su propia identidad como resuelta o unificada, como resultado de la fantasía de sí mismo como persona unificada que se formó durante el estadio del espejo. Esto, según este tipo de pensamiento psicoanalítico, constituye el origen contradictorio de la identidad.

De este modo, la identidad se forma en realidad a lo largo del tiempo por medio de procesos inconscientes, en lugar de ser algo innato en la consciencia en el momento del nacimiento. Siempre hay algo de imaginario o fantaseado acerca de su unidad. Siempre sigue siendo incompleta, siempre está en proceso, siempre está en formación. Así, más que hablar de identidad como algo acabado, deberíamos hablar de identificación, y concebirla como un proceso inacabado. La identidad se yergue, no tanto de una plenitud de identidad que ya está dentro de nosotros como individuos, sino de una falta de totalidad, la cual es llenada desde fuera de nosotros, por medio de las maneras en que imaginamos que somos vistos por otros.

En la dinámica cultural influyen varios procesos sociales que repercuten en la construcción de la identidad individual y colectiva, entre estos procesos de globalización y transnacionalización, se encuentran prácticas sociales económicas, políticas, demográficas y culturales, además fenómenos sociales como la migración, la política, las redes sociales virtuales, los medios de comunicación y la destrucción del ambiente; los cuales atraviesan fronteras nacionales, integrando y conectando comunidades en nuevas organizaciones, en nuevas combinaciones de espacio-tiempo, haciendo que el mundo este más interconec- 
tado, todo lo cual se ha facilitado por el desarrollo de la tecnología en las comunicaciones y ha generado un cambio en la concepción de las identidades nacionales, sin que estas desaparezcan, estas identidades nacionales siguen siendo fuertes con relación a sus identidades locales, regionales y comunitarias (Hall, 1992); si bien los grupos de poder pueden dislocar fronteras espaciales, culturales y demográficas al controlar las telecomunicaciones y sus contenidos, en el sentido inverso las identidades nacionales o identidades locales poseen aspectos de diferenciación y un sentido de pertenencia arraigado a su contexto histórico que hacen frente a estos.

En la construcción de identidad desde la otredad, se toman los análisis de las producciones indígenas desarrollados por la antropóloga Briones en su publicación de Cultura, identidades y fronteras: una mirada desde las producciones del cuarto mundo, da cuenta de una otredad cultural, donde se construye una identidad en relación al otro, construir la otredad como objeto disciplinar de construcción del otro, propone tres momentos o formas que se desarrollan en complejas superposiciones: el primero: el otro como otro en sí; el segundo: el otro como efecto de relaciones de interacción/dominación; y el tercero: el otro como efecto de una marcación que opera la invisibilización del nosotros como lugar de poder, como máscara de una máscara (Briones, 1996).

Desarrollaremos a continuación estos tres momentos/formas de construir identidad desde la otredad en la moda de la indumentaria, basados en los textos de Simmel (2017 [1905]), Weber (1944, 1964), Godart (2012), Barnard (2007), Kamura (2005), entre otros. El primero, el otro como otro en sí, que propone ver al otro como otro en el tiempo, como un antepasado coexistente en el presente, reconocer al otro del pasado como un otro en el espacio geográfico y social, como un referente de un modelo de distintas formas de adaptación (Briones, 1996); en este sentido partimos de la moda como un "hecho social que implica profundamente a las personas y a los grupos sociales y cuya comprensión da cuenta de lo humano en su totalidad" (Godart, 2012, p. 17), la moda es un hecho social total, ya que es simultáneamente artístico, económico, político, sociológico y agregamos histórico, en sentido de una historia de la moda analizada solo desde la evolución de sus contenidos; pero una reflexión históricamente de su significación, con proceso sociales adaptados al estado de cada cultura tanto individual como social, y la satisfacción de aquellas dos opuestas tendencias (Simmel, 2017).

Según su contexto tecnológico de la producción textil para el desarrollo de la moda en la indumentaria, podemos apreciar que la producción de hilandería, tejeduría y confección se transformó pos guerra con la producción seriada, en sus contextos políticos la indumentaria ha sido portadora de mensajes anarquistas, como es el caso de la diseñadora inglesa Viviane Westwood, que junto a su novio empezaron a utilizar prendas desgarradas, con apliques de puntas, cadenas de bicicletas, complementados con peinados y maquillajes desafiantes como un símbolo a su contraposición con la anarquía, sus expresiones se convirtieron en el estilo punk que se difundieron a un grupo social que compartía su ideología y formó una identidad social, el estilo punk que se formó desde esta ideología prevalece en el tiempo y es tomado como referente de diseñadores contemporáneos.

La moda en la indumentaria es cíclica, los estilos pasados son un referente para los diseñadores actuales, el ver a nuestros antepasados forma parte del proceso creativo para la inspiración y conceptualización, los cuales son reinterpretados con propuestas contempo- 
ráneas que utilizan comúnmente recursos tecnológicos del presente. El ver al otro como otro en sí, que se desarrolló en condiciones de un espacio y tiempo particular, en el diseño nos permite reconocer el contexto, las limitaciones y las adaptaciones que tuvieron la concreción de prendas, ponerlas en valor y mediante este análisis crítico-reflexivo generar propuestas de diseño innovadoras-reflexivas.

Para esta propuesta reflexiva se une el segundo momento-forma que propone Briones (1996), donde nos refiere a el otro como efecto de relaciones de interacción/dominación, con el tercero donde se plantea a el otro como efecto de una marcación que opera la invisibilización del nosotros como lugar de poder, como máscara de una máscara, se analiza que el tercero es un resultado del segundo, es decir el repensar la otredad como efecto de relaciones de interacción-dominación, que se evidencia en la producción cultura de varios países de Latinoamérica como el resultante de una colonización y de sus relaciones políticas asimétricas que se auto legitiman esgrimiendo las diferencias culturales de ese otro. Estas realidades lejos de marcar a las identidades locales como colonizados, generó una producción cultural más amplia donde se han generado múltiples formas de otredad, que consideran las interacciones, relaciones y diferencias sociales en términos de género, raza, clase y manifestaciones culturales; enfatizando las cualidades especulares de las prácticas identitarias.

Estos dos momentos-formas nos permite mirar la construcción de la identidad como un sistema de relaciones dinámicas que se construyen en el día a día, más no un proceso estático, una dinámica donde las personas no solo se deben encontrar a sí mismo como ser único, sino como un ser que convive en un espacio social con diferentes factores que generan un sentido de pertenencia, una construcción de identidad desde el otro, reconociendo las diferencias entre las realidades que se viven entre los contextos.

En la actualidad la construcción de la identidad se aleja de una concepción estática y estructurada, contrario a esto la identidad se edifica en individuos que construyen sociedades, que interactúan en contextos diversos y en donde "los procesos de construcción de identidad están relacionados con las concepciones y representaciones del ser en relación con el otro" (Ulloa, 2005, p. 11), se alude que todavía en el imaginario occidental permanecen estereotipos que marcan y restringen las identidades de los otros. Cuando se habla de individualidades y de tendencia más libre y tolerante para presentarse a sí mismo y frente a los otros, se da por cierto que existe una organización subyacente que es como un hilo conductor en un contexto donde las acciones forman parte de una trama más amplia de dependencias mutuas (Saulquin, 2014). De manera análoga, la identidad individualista se concibe como un conjunto de propiedades único, que reside en el individuo y que se va fijando en una trayectoria de vida, pero estas propiedades tienen a la vez un aspecto compartido, que se manifiesta en la vida asociativa de la gente a la podemos llamar identidad colectiva, como una organización de la sociedad en grupos, que se encuentran y se reúnen de manera voluntaria, y en formación de diversas conciencias identitarias del grupo. La identidad colectiva se forma, entonces, a partir de un común denominador, de una igualdad de esencia (Altamirano, 2002).

Llevaremos esta construcción de identidad hacia la moda en la indumentaria desde una contraposición que proviene del dilema de la vida en relación con la forma, guiamos el planteo desde las publicaciones de Simmel (2017), quien plantea la moda es una Lebens- 
form, una forma de vida, como el movimiento y el esfuerzo por el cual nuestra conciencia busca ajustar un contenido a una forma; forma como orden plástico, modificable, vivo, una dirección y una tendencia más que una cosa.

La moda es la imitación de un modelo dado, que satisface la necesidad de adaptación hacia la sociedad, lleva a los individuos por caminos conocidos donde todos transitan, satisface además la necesidad de distinción y diferenciación, la tendencia a la disimilitud y el deseo de cambio y contraste; se plantea que el individuo mantiene una constante búsqueda de adaptación a la sociedad y diferenciación dentro de ella, encuentra en las prendas de vestir esta doble coyuntura. Según Weber (1964), el simple hecho de que alguien acepte para sí una actitud determinada, aprendida en otros y que parece conveniente para sus fines, no es una acción social en nuestro sentido, se evidencia que en este caso no orientó su acción por la acción de otros, sino que por medio de la observación se dio cuenta de ciertas probabilidades objetivas, dirigiendo por medio de estas consideraciones se conducta. Su acción, por tanto, fue determinada crucialmente por la de otros, pero no por el sentido en aquélla contenido. Cuando, al contrario, se imita una conducta ajena porque está de moda o porque vale como distinguida en cuanto estamental, tradicional, códigos sociales, referentes, ejemplar o por cualesquiera otros motivos semejantes, entonces sí tenemos lo que Weber manifiesta como una relación de sentido, bien respecto de la persona imitada, de terceros o de ambos, generando transiciones.

Desde temprana edad imitamos lo que vemos en el otro; es decir, nos reconocemos en el otro y este reconocimiento del otro nos permite comprender las formas de interacción con la colectividad, la moda genera la imitación de un modelo de aspectos morfológicos, cromáticos, estéticos y simbólicos; además influye en procesos económicos y culturales, donde se desarrolla un complejo sistema de la moda, que establece a su vez códigos vestimentarios por ocasión, género, ideología y otros aspectos sociales. Buscamos desarrollar una identidad individual que posean factores de diferenciación, características exclusivas, aspectos originales y un estilo único que nos permitan sobresalir de un grupo social. El sistema moda como colectivo, como producción masiva y direccionada al consumismo se ha ido desarticulando en los últimos años, toman fuerza las individualidades y conciencias particulares, entre las causas que afirman este suceso se encuentra la influencia de la era tecnológica que transforma la forma de relacionarse entre las personas, también está el fenómeno de las redes sociales que ha ido ganando grandes espacios entre las relaciones personales, exponiendo vidas privadas, creando vidas virtuales, ofreciendo información al instante y dando paso a la manipulación de información, estos aspectos configuran al mundo desde otras perspectivas, teniendo nuevas miradas y formas de percibir la realidad. Otras formas de mirar y percibir la realidad rompen paradigmas tradicionales de un pensamiento lineal y nos guían hacia un pensamiento complejo de interacciones y relaciones de sistemas, en este devenir el pensar de una manera integral con predominio en aspectos sostenibles y sustentables, el diseño toma un papel importante en la toma de decisiones de procesos productivos y de creación, la autora Saulquin (2014) menciona en su libro Política de las apariencias. Nueva significación del vestir en el contexto contemporáneo, que en la actualidad se instala otra mirada abarcadora de aspectos socioculturales, económicos, industriales y ambientales, que buscan crear una diferente matriz de desarrollo basada en la reducción y en sustentabilidad, que se puede lograr con una adaptación de la produc- 
ción masiva y el consumo voraz, consolidando el poder de las personas y la importancia de los lazos sociales, se propone entonces como perspectiva necesaria un diseño de prendas que debe ser eficaz, estable y sostenible, proyectado con responsabilidad y conciencia social, bajo modelos de economía circular. Es importante redefinir los códigos de consumo masivo sin conciencia, que hacían del exceso y del desperdicio una constante, basados en la premisa fundamental de adquirir productos de moda bajo el pensamiento lineal de producir y consumir prendas nuevas en cada temporada.

\section{Construcción de la identidad desde la otredad de la indumentaria en el Ecuador}

Es importante reconocer que en el Ecuador la producción de moda en la indumentaria no sigue las dinámicas establecidas por las tendencias globales estacionales, sus lógicas de producción responden a aspectos demográficos que dividen al territorio en cuatro regiones con características climáticas diferentes, en este sentido la producción de indumentaria se desarrolla según su locación más que la estación.

Proponemos una primera forma-momento para la construcción de identidad que se ha desarrollado desde la propuesta de Briones (1996), mirar al otro como otro en sí, no dirigimos a comunidades de grupos sociales donde prevalecen culturas ancestrales que han hecho frente a la conquista de los incas hacia los cañaris, de la colonización española a lo largo del todo el territorio y en los últimos años las petroleras transnacionales que se asientan sobre la amazonia, a pesar de estos hechos son varias las culturas que preservan su vestimenta, costumbres, ideologías y tradiciones, podemos nombrar algunas según su ubicación geográfica, en la región sierra los otavaleños, saraguros, salasacas y cañaris; en la región costa a los tsáchilas, chachis y huancavilcas; y en la amazonía los huaronis, shuar, achuar, andoas, kichwa, secoyas, shiwiar y cofanes, son identidades indígenas que denotan una cultura nacional.

El discurso de la cultura nacional no es tan moderno como podría parecer, construye identidades que están situadas ambiguamente entre el pasado y el futuro, se ubican entre la tentación de retornar a las glorias antiguas y el impulso de seguir adelante, entrando cada vez más profundamente en la modernidad. A veces las culturas nacionales son tentadas a volver a una situación anterior, a refugiarse defensivamente en ese tiempo perdido, cuando la nación era grande, y establecía identidades pasadas. Éste es el elemento regresivo y anacrónico de la historia cultural nacional. Sin embargo, a menudo este mismo retorno al pasado esconde una lucha por movilizar al pueblo a purificar sus filas, para expulsar a los otros que amenazan su identidad, y apercibirse para la acción para una nueva marcha hacia adelante.

A pesar de los intentos por conservar las manifestaciones culturales de estos grupos sociales con declaratorias patrimoniales tanto materiales, como inmateriales, es evidente una pérdida de saberes y tradiciones, debido en gran medida a la migración de una considerable parte de la población indígena, podemos hablar así de una desarrollo de identidad individual y colectiva circundada por el fenómeno social de la aculturación, la cual se 
define según Valdés (2015) como la transferencia de elementos o rasgos de una cultura a otra, cuyo proceso y dispositivos podemos deducir, porque su manifestación ha ocurrido en un tiempo específico histórico, considera la aculturación como la transmisión cultural en marcha, como un fenómeno social histórico con pasado, presente, y futuro, que puede someterse a observación y brindar explicaciones del dónde, cómo, cuándo y, quién está involucrado en determinado acontecimiento observable en el campo cultural; la aculturación es un hecho que refleja una realidad social actual de nuestro país.

Planteamos así, la construcción de una identidad desde la otredad en dos modos: la primera desde la relación interacción/dominación como una aculturación de la cultura global hacia la cultura local, donde tomamos como referencia al otro con gran influencia de corrientes occidentales, especialmente de Estados Unidos que se refleja en el uso de marcas que se que comercializan prendas de vestir que son producidas masivamente en forma de máquina en países tercermundistas de Asia y América Latina, con un alto valor simbólico de posicionamiento de marca instauradas con mensajes de calidad, tendencia, moda, clase social, poder adquisitivo y país de origen. Esta realidad ha desarrollado un valor de consumo por lo externo, donde la producción local tiene que lidiar con una cultura de consumo que da poco valor a la producción propia y es cuestionada por su origen, calidad y precio. Bajo este panorama surge el segundo modo de una construcción de una identidad desde la otredad en la indumentaria como una aculturación de la cultura local hacia la cultura global, bajo la búsqueda de una identidad individual y colectiva en producción de indumentaria, se propone un reto de desarrollar una identidad propia aspiracional para el otro, que comunique un sentido de pertenencia, fortalezca aspectos de diferenciación, fomente la creación y desarrolle un consumo cultural de lo local.

Algunos teóricos culturales argumentan que la tendencia hacia mayor interdependencia global está conduciendo al quiebre de todas las identidades culturales fuertes y está produciendo aquella fragmentación de códigos culturales, aquella multiplicidad de estilos, aquel énfasis en lo efímero, en la fugacidad, en lo pasajero y en la diferencia y el pluralismo cultural que Kenneth Thompson (1996) describió, pero en una escala global, lo que podríamos llamar lo posmoderno global. Los flujos culturales y el consumismo global entre las naciones crean la posibilidad de identidades compartidas, como clientes de los mismos bienes, de los mismos servicios, y como audiencias de los mismos mensajes e imágenes, entre personas que están alejadas unas de otras en el tiempo y el espacio.

A medida que las culturas nacionales están expuestas a influencias externas, se vuelve más difícil preservar las identidades culturales intactas, o prevenir que se debiliten a raíz del bombardeo cultural y la infiltración. Las personas en pueblos pequeños aparentemente remotos y pobres en países del Tercer Mundo pueden recibir en la privacidad de sus hogares los mensajes e imágenes de las culturas ricas y consumistas de Occidente, abastecidos a través de televisiones o de la radio, los cuales los vinculan a la aldea global de las nuevas redes de comunicación.

La globalización e inmediatez por el desarrollo de la tecnología y procesos de comunicación ha permitido que el mundo se empequeñezca y perdamos el sentido de ubicación geográfica, se pensaría que ésta anula todo tipo de identidad, lo cual no es del todo cierto, también da lugar a fortalecer identidades individuales y colectivas con un sentido de pertenencia hacia un territorio, cultura, etnia, familia, comunidad, país o manifestación 
cultura; la globalización cultural crea nuevas oportunidades para la producción de indumentaria, para el diseño y para la moda.

Nos enmarcamos en la mirada de Kawamura (2005), donde la moda juega un papel importante en la manifestación con sutiles diferencias y distinciones, en un mundo moderno con mayores oportunidades para todos, con una competencia más democrática y donde prevalece el derecho a participar en la competencia, en este marco de un mundo una comunicación veloz, donde los canales de comercialización son asequibles, los mercados son alcanzables, se crea un espacio de oportunidades para que producción de indumentaria local.

Como reflexión provisoria, la moda en la indumentaria es un canal de comunicación potente que promueve la imitación y fomenta la diferenciación, se propone construir una identidad con mirada reflexiva de lo que fuimos en un momento histórico, con reconocimiento a nuestro contexto, nuestra cultura, nuestras fortalezas locales y que encuentran oportunidades en un mundo de comunicación globalizada.

\section{Lista de referencias bibliográficas}

Altamirano, C. (2002). Términos Críticos de la Sociología de la Cultura. Buenos Aires: Paidós. Barnard, M. (2007). Fashion Theory. London: Routledge.

Barthes, R. ([1967] 1978). El sistema de la moda. Barcelona: Gustavo Gilí S.A.

Bourdieu, P. (2010). El sentido social del gusto. Buenos Aires: Siglo veintiuno editores.

Briones, C. (1996). Culturas, identidades y fronteras: una mirada desde las producciones del cuarto mundo. Revista de Ciencias Sociales.(5), pp. 121-133 / 122-123.

Corporación de estudios y publicaciones. (2009). Constitución de la República del Ecuador, Comentarios, Legislación Conexa, Concordancias. Quito: Legislación y Codificación.

Gimenez, G. (2005). Teoría y Análisis de la Cultura. México: Icocult.

Godart, F. (2012). Sociología de la moda. (A. Díaz, Trans.) Buenos Aires, Argentina: Edhasa.

Hall, S. (1992). La cuestión de la identidad cultural. Modernity and Its Futures, pp. 273316-366 - 371.

Kawamura, Y. (2005). Fashion-ology. An Introduction to Fashion Studies. New York: Berg.

Mayer, E. (1984). Los atributos del hogar: economía doméstica y la encomienda en el Perú colonial. Revista Andina(2).

Ramos, A. (1992). El indio hiperreal. Serie Antropología 135, pp. 1-18.

Saulquin, S. (2014). Política de las apariencias. Nueva significación del vestir en el contexto contemporáneo. Buenos Aires, Argentina: Paidós.

Simmel, G. (2014). Fashion. Chicaro Journals, 541-558.

Simmel, G. (2017). Filosofía de la moda. Madrid: Casimiro.

Thompson, K. (1996). Social Pluralism and Post-modernity. In S. H. al, Modernity: An Introduction to Modern Societies (pp. 564-594). Cambridge: Blackwell.

Ulloa, A. (2005). Las representaciones sobre los indígenas en los discursos ambientales y de desarrollo sostenible. Políticas de economía, ambiente y sociedad en tiempos de globalización, pp. 1-21. 
Valdés, M. (2015). La vigencia del concepto de la Aculturación: alcances y limitaciones. México.

Veneziani, M. (2012). Moda, economía y sociedad. Buenos Aires: Nobuko.

Wachtel, N. (1990). Temps à retours restructuration indiennes. Le Retour des Ancestres les Indies llrus de Bolivie. XXe-XVIe Siégle. Essai d'Historie Régressive.

Weber, M. (1944, 1964). Economía y Sociedad. Esbozo de sociología comprensiva. Madrid: Fondo de Cultura Económica.

White, N., \& Griffiths, I. (2000). The Fashion Business. Theory, Practice, Image. New York: Berg.

Wilde, G. (2009, 07 27). La problemática de la identidad en el cruce de perspectivas entre antropología e historia. Reflexiones desde el campo de la etnohistoria. Disponible en: Ciudad Virtual de Antropologia y Arqueologia es un emprendimiento del Equipo NAyA.: http:// www.antropologia.com.ar

Abstract: In an approach to know how we build our own identity that is recognized from the existence of the other, a construction that feeds on the context that surrounds it and the relationships in social dynamics, approaches from various authors such as Hall, Wilde, Briones and Ulloa, to get to analyze in the cultural dynamics, the identity recognized from the otherness in the dress codes of fashion from the analyzes of Simmel, Veneziani, Saulquin, among others.

Keywords: Identity - fashion - otherness - social dynamics - codes - clothing - culture society - history - sociology.

Resumo: Numa abordagem para saber como construímos a nossa própria identidade que se reconhece a partir da existência do outro, uma construção que se alimenta do contexto que a rodeia e das relações na dinâmica social, abordagens de vários autores como Hall, Wilde, Briones e Ulloa, para chegar a analisar na dinâmica cultural, a identidade reconhecida a partir da alteridade nos códigos de vestimenta da moda a partir das análises de Simmel, Veneziani, Saulquin, entre outros.

Palavras chave: Identidade - moda - alteridade - dinâmica social - códigos - roupas - cultura - sociedade - história - sociologia.

[Las traducciones de los abstracts fueron supervisadas por el autor de cada artículo] 